\title{
PERBANDINGAN ANTARA PENGGUNAAN PENGIKAT DAN HUMEKTAN TERHADAP SIFAT FISIK SEDIAAN PASTA GIGI EKSTRAK ETANOL 96\% DAUN SOSOR BEBEK (Bryophylum pinnatum [Lam.] Oken)
}

\author{
COMPARATIVE THE EFFECT OF USING BINDER AND \\ HUMECTANTS ON THE PHYSICAL PROPERTIES OF \\ TOOTHPASTE $96 \%$ ETHANOL EXTRACT OF \\ (Bryophylum pinnatum [Lam.] Oken)
}

\author{
Rahmah Elfiyani, Naniek Setiadi. R., Sri Dwi Mei, Siti Maesaroh \\ Fakultas Farmasi dan Sains. UHAMKA Jakarta \\ Email : rahmaelfiyani@yahoo.com
}

\begin{abstract}
ABSTRAK
Daun sosor bebek (Bryophyllum pinnatum [Lam.] Oken) merupakan bahan alam yang diketahui memiliki aktivitas antibakteri terhadap Streptococcus mutans. Pada pembuatan pasta gigi digunakan Xanthan gum dan Natrium Karboksimetil selulosa sebagai pengikat, serta menggunakan sorbitol dan gliserin sebagai pelembab (humektan). Penelitian ini bertujuan untuk membandingkan pengaruh penggunaan bahan pengikat dan pelembab (humektan) terhadap stabilitas fisik pasta gigi ekstrak etanol 96\% daun sosor bebek. Pasta gigi dibuat dalam 5 formula dengan konsentrasi xanthan gum sebagai pengikat 1,$5 ; 1,75 ; 2 ; 2,5 ; 3 \%$, dan 5 formula dengan konsentrasi sorbitol sebagai humektan 10;20;30; 40; 50\%. Tiap formula dievaluasi selama 6 minggu meliputi uji organoleptik, homogenitas, $\mathrm{pH}$, viskositas, tinggi busa. Selain itu dilakukan uji freeze thaw dan sentrifugasi. Hasil data viskositas formula dengan bahan pengikat xanthan gum $232.700-555.300$ cps, sedangkan hasil data viskositas formula dengan bahan humektan sorbitol 14.133 - 75.600 cps. Berdasarkan hasil, dapat disimpulkan bahwa peningkatan konsentrasi pengikat dalam formula lebih efektif untuk meningkatkan konsistensi dan viskositas sediaan dibandingkan dengan peningkatan konsentrasi pelembab sehingga meningkatkan stabilitas sifat fisik sediaan pasta gigi.
\end{abstract}

Kata kunci: pasta gigi, xanthan gum, sorbitol, ekstrak daun sosor bebek, sifat fisik.

\begin{abstract}
Bryophyllum pinnatum [Lam.] Oken are natural materials that have antibacterial activity against Streptococcus mutans. In the manufacture of toothpaste used xanthan gum and sodium carboxymethyl cellulose as a binder, as well as the use of sorbitol and glycerin as a humectant. This study aimed to compare the effect of using a binder and humectants to the physical stability of toothpaste $96 \%$ ethanol extract of Bryophyllum pinnatum. Toothpaste made in five formulas with
\end{abstract}


concentrations of xanthan gum as a binder of $1.5 ; 1.75 ; 2 ; 2.5 ; 3 \%$, and 5 formulas with concentrations of sorbitol as a humectant $10 ; 20 ; 30 ; 40 ; 50 \%$. Each formula was evaluated for 6 weeks, including organoleptic test, homogeneity, $\mathrm{pH}$, viscosity, high foam. It also tested the freeze thaw and centrifugation. Results of viscosity data from formula with xanthan gum-glycerine were 232.700-555.300 cps, while the viscosity data results from the formula with sodium carboxymethyl selulosa- sorbitol were 14.133-75.600 cps. Based on the results, it can be concluded that the increased concentration of binder in the formula is more effective to improve the consistency and viscosity of the preparation compared to the increase of the concentration of moisture thereby enhancing the stability of the physical properties of the preparation of toothpaste.

Keywords : toothpaste, xanthan gum, sorbitol, Bryophyllum pinnatum extract, physical properties

\section{PENDAHULUAN}

Adanya makanan (terutama

gula), kerentanan gigi, dan kerusakan gigi akibat bakteri Streptococcus mutans merupakan 3 faktor utama dalam perkembangan terjadinya karies gigi (Mitsui, 1997). Untuk mencegah karies gigi, maka dibutuhkan bahan-bahan alam yang mengandung zat aktif antibakteri.

Salah satu bahan alam yang dapat digunakan yaitu daun sosor bebek (Bryophyllum pinnatum [Lam.] Oken). Berdasarkan penelitian, ekstrak etanol $96 \%$ daun sosor bebek mampu menghambat pertumbuhan bakteri S.mutans dengan Kadar Hambat Minimum (KHM) sebesar 5\% (Oktorita, 2010). Penggunaan dalam bentuk ekstrak kurang praktis, untuk itu perlu dibuat sediaan pasta gigi agar berkhasiat dan stabil secara fisik maupun kimia. Salah satu komponen penting pasta gigi adalah bahan pengikat dan pelembab, kedua bahan tersebut dapat mempengaruhi konsistensi dan viskositas sehingga mempengaruhi stabilitas fisik sediaan. Pengikat digunakan untuk mencegah pemisahan bahan padat dan bahan cair (Mitsui, 1997). Pelembab ditambahkan ke dalam pasta gigi untuk mencegah terjadinya pengeringan dan pengerasan pasta, serta dapat melindungi komponenkomponen yang terikat kuat di dalam bahan yang belum mengalami kerusakan termasuk kadar air, kadar 
lemak dan komponen lainnya (Jackson, 1995). Pada penelitian ini, xanthan gum digunakan konsentrasi 1,5-3\% dengan gliserin digunakan konsentrasi $10 \%$, sedangkan natrium karboksimetil selulosa digunakan konsentrasi $1 \%$ dengan sorbitol digunakan konsentrasi 10-50.

Alat-alat yang digunakan dalam penelitian ini terdiri dari: timbangan analitik, vaccum Rotary Evaporator, oven, mixer, cover glass, object glass, $\mathrm{pH}$ meter (HI 110 series), viskometer (Brookfield tipe RVDVE), centrifuge, dan alat-alat gelas.

Bahan-bahan yang digunakan dalam penelitian ini terdiri dari: daun sosor bebek yang diperoleh dari BALITTRO. Etanol 96\% (technical grade), kalsium karbonat (technical grade), sorbitol dan natrium sakarin (food grade) yang diperoleh dari PBF Harum Kimia. Gliserin, natrium lauril sulfat, minyak permen (food grade), Natrium Karboksimetil Selulosa, metil paraben, dan propil paraben yang diperoleh dari $\mathrm{PBF}$ Citra Kimia. Xanthan gum (food grade) yang diperoleh dari PT. Samiraschem Indonesia, serta aquades.

\section{METODE PENELITIAN}

Jalannya Penelitian

1. Pembuatan ekstrak etanol $96 \%$ daun sosor bebek (Depkes RI, 2008)

Daun sosor bebek segar diekstraksi dengan metode maserasi Sejumlah $\pm 15 \mathrm{~kg}$ daun sosor bebek segar dirajang, dimaserasi dengan menggunakan $30 \mathrm{~L}$ etanol $96 \%$ (sampai terendam) selama 3 hari sambil sesekali diaduk, kemudian disaring. Ulangi proses penyarian sekurang-kurangnya dua kali dengan jenis dan pelarut yang sama. Filtrat yang didapat, kemudian dipekatkan dengan rotary evaporator dengan suhu $\pm 50^{\circ} \mathrm{C}$ dan kecepatan pada skala 5 selama \pm 2 jam. Ekstrak yang didapat dipanaskan dalam oven pada suhu $45^{\circ} \mathrm{C}$ selama \pm 4 hari hingga didapatkan ekstrak kental.

2. Karakterisasi ekstrak etanol $96 \%$ daun sosor bebek

a. Organoleptik ekstrak kental daun sosor bebek

Pemeriksaan organoleptik meliputi rasa, bau, dan warna 
b. Penetapan susut pengeringan

(Depkes RI, 2000)

Ekstrak ditimbang saksama lebih kurang $1 \mathrm{~g}$, dalam botol kaca dangkal bertutup yang sebelumnya telah dipanaskan dengan suhu $105^{\circ} \mathrm{C}$ selama 30 menit dan telah ditara. Ekstrak diratakan dalam botol kaca dengan menggoyangkan botol. Botol dimasukkan ke dalam oven, tutupnya dibuka, panaskan pada suhu $105^{\circ} \mathrm{C}$ selama 1 jam. Botol didinginkan dalam desikator selama 15 menit, kemudian ditimbang hingga bobot tetap.

c. Identifikasi senyawa saponin dan flavonoid

1) Saponin (Depkes RI, 1979)

Sampel dimasukkan ke dalam tabung reaksi, ditambahkan $10 \mathrm{ml}$ air, dan kemudian kocok kuatkuat selama 10 menit. Positif jika terbentuk buih kurang dari 10 menit.

2) Flavonoid (Harborne, 1987)

Sampel dicampur dengan 5 ml etanol, dikocok, dipanaskan, dikocok lagi kemudian disaring, dan ditambahkan $\mathrm{Mg}$ 0,2 g serta 3 tetes $\mathrm{HCl}$ pekat pada masingmasing filtrat. Terbentuknya warna merah pada lapisan etanol menunjukkan adanya flavonoid.

1. Penyusunan formula pasta gigi

Penyusunan formula pasta gigi ekstrak etanol $96 \%$ daun sosor bebek dengan Natrium Karboksimetil Selulosa - sorbitol dapat dilihat pada Tabel I. Penyusunan formula pasta gigi ekstrak etanol $96 \%$ daun sosor bebek dengan xanthan gum sorbitol dapat dilihat pada Tabel II. 
Tabel I. Formula Pasta Gigi Ekstrak Etanol 96\% Daun Sosor Bebek Dengan Natrium Karboksimetil Selulosa - Sorbitol

\begin{tabular}{ccccccc}
\hline \multirow{2}{*}{ Bahan } & \multirow{3}{*}{ Kegunaan } & \multicolumn{5}{c}{ Formula (\%) b/v) } \\
\cline { 3 - 7 } & & F1 & $\mathbf{F 2}$ & $\mathbf{F 3}$ & $\mathbf{F 4}$ & $\mathbf{F 5}$ \\
\hline Ekstrak kental daun sosor bebek & Bahan aktif & 3,93 & 3,93 & 3,93 & 3,93 & 3,93 \\
Natrium Karboksimetil Selulosa & Pengikat & 1 & 1 & 1 & 1 & 1 \\
Natrium Sakarin & Pemanis & 0,2 & 0,2 & 0,2 & 0,2 & 0,2 \\
Kalsium karbonat & Abrasif & 35 & 35 & 35 & 35 & 35 \\
Natrium lauril sulfat & Foaming agent \& & 0,5 & 0,5 & 0,5 & 0,5 & 0,5 \\
& detergent & & & & & \\
Minyak permen & Perasa & 0,5 & 0,5 & 0,5 & 0,5 & 0,5 \\
Sorbitol & Humektan & 10 & 20 & 30 & 40 & 50 \\
Metil paraben & Pengawet & 0,18 & 0,18 & 0,18 & 0,18 & 0,18 \\
Propil paraben & Pengawet & 0,02 & 0,02 & 0,02 & 0,02 & 0,02 \\
Air sampai dengan & Pelarut & 100 & 100 & 100 & 100 & 100 \\
\hline & & & & & &
\end{tabular}

Tabel II. Formula Pasta Gigi Ekstrak Etanol 96\% Daun Sosor Bebek Dengan Xanthan gum Gliserin

\begin{tabular}{ccccccc}
\hline \multirow{2}{*}{ Bahan } & \multirow{6}{*}{ Kegunaan } & \multicolumn{5}{c}{ Formula $(\% \mathbf{b} / \mathbf{v})$} \\
\cline { 3 - 7 } & & $\mathbf{F 6}$ & $\mathbf{F 7}$ & $\mathbf{F 8}$ & $\mathbf{F 9}$ & $\mathbf{F 1 0}$ \\
\hline Ekstrak kental daun sosor bebek & Bahan aktif & 3,93 & 3,93 & 3,93 & 3,93 & 3,93 \\
Xanthan gum & Pengikat & 1,5 & 1,75 & 2,0 & 2,5 & 3,0 \\
Na. Sakarin & Pemanis & 0,2 & 0,2 & 0,2 & 0,2 & 0,2 \\
Kalsium karbonat & Abrasif & 45 & 45 & 45 & 45 & 45 \\
Natrium lauril sulfat (NLS) & Foaming agent \& & 2 & 2 & 2 & 2 & 2 \\
& detergent & & & & & \\
Minyak permen & Perasa & 0,4 & 0,4 & 0,4 & 0,4 & 0,4 \\
Gliserin & Humektan & 25 & 25 & 25 & 25 & 25 \\
Metil paraben & Pengawet & 0,18 & 0,18 & 0,18 & 0,18 & 0,18 \\
Propil paraben & Pengawet & 0,02 & 0,02 & 0,02 & 0,02 & 0,02 \\
Air sampai dengan & Pelarut & 100 & 100 & 100 & 100 & 100 \\
\hline & & & & & &
\end{tabular}

2. Pembuatan pasta gigi (Lieberman, 1996)

Masing-masing pengikat (Xanthan gum dan Natrium Karboksimetil Selulosa) didispersikan dengan sebagian pelembab (gliserin dan sorbitol) (M1). Metil paraben dan propil paraben dilarutkan dengan sebagian gliserin (M2). Ekstrak daun sosor bebek didispersikan dengan sebagian gliserin (M3). Natrium sakarin dilarutkan dengan sebagian air (M4). $\mathrm{M} 1+\mathrm{M} 2+\mathrm{M} 3+\mathrm{M} 4$ dicampurkan ke dalam wadah dan ditambahkan sisa air, kemudian diaduk dengan mixer hingga mengental dan homogen. Kalsium karbonat ditambahkan ke dalam campuran tersebut sedikit demi sedikit sambil 
diaduk dengan mixer hingga homogen dengan kecepatan konstan. NLS didispersikan dalam sisa gliserin dan kemudian dicampurkan dalam campuran tersebut diaduk perlahan-lahan hingga homogen.

Minyak permen dimasukkan terakhir dalam campuran tersebut lalu diaduk hingga homogen. Sediaan yang telah jadi dimasukkan ke dalam wadah. Tahap terakhir, dilakukan evaluasi sediaan selama 6 minggu.

3. Evaluasi

Evaluasi pasta gigi dilakukan selama 6 minggu pada suhu kamar $\left(25^{\circ}-30^{\circ} \mathrm{C}\right)$ yang meliputi:

1) Organoleptik (SNI)

Pemeriksaan organoleptik seperti bentuk, bau, warna, dan homogenitas yang dilakukan secara visual.

2) Homogenitas

Pasta gigi dioleskan di atas kaca objek, ditutupi dengan cover glass, diamati secara visual. Homogenitas sediaan diamati dari permukaan yang terbentuk pada kaca objek.
3) Pengukuran pH (Depkes RI, 1995)

Pengukuran $\mathrm{pH}$ dilakukan dengan menggunakan alat $\mathrm{pH}$ meter, sebelum digunakan $\mathrm{pH}$ meter dikalibrasi dengan larutan dapar $\mathrm{pH}$ 4,0 (dapar kalium biftalat) dan larutan dapar $\mathrm{pH}$ 7,0 (dapar fosfat ekimolal). Setelah dikalibrasi, celupkan $\mathrm{pH}$ meter kedalam sediaan pasta gigi.

4) Pengukuran tinggi busa (Rieger, 1985)

a) Pengukuran tinggi busa dalam air suling

Tinggi busa dari $0,1 \%$ larutan sediaan dalam air suling, dapat diukur menggunakan gelas ukur. Pengukuran dilakukan dengan menggunakan metode sederhana yang akan menghasilkan hasil yang dapat disamakan dengan tes Ros miles antara lain: $25 \mathrm{ml}$ larutan dimasukkan ke dalam gelas ukur 100 $\mathrm{ml}$, kocok dengan cara membalikkan gelas ukur lebih dari 5 kali, lalu segeralah amati tinggi busa yang dihasilkan. 
b) Pengukuran tinggi busa dalam air sadah

Prosedur serupa dengan pengukuran tinggi dan stabilitas busa dalam air suling. Namun air yang digunakan merupakan air sadah yang dibuat dengan melarutkan 0,233 $\mathrm{g}$ kalsium karbonat dan $0,116 \quad \mathrm{~g}$ magnesium karbonat dalam air suling sedikit demi sedikit dan ditambahkan $\mathrm{HCl}$ setetes demi setetes hingga larut dalam labu tentu ukur 1000 ml, dan ditambahkan aqudest hingga tanda pada labu ukur.

5) Uji pemisahan fase (Lachman, 1994)

a) Metode sentrifugasi

Sampel dimasukkan di dalam tabung sentrifugal, kemudian alat diatur dengan kecepatan 3750 rpm selama 5 jam.

b) Metode freeze thaw

Siklus pemisahan fase dengan metode freeze thaw pada sediaan pasta gigi dilakukan selama 6 siklus. Setiap siklus diamati setelah 2 hari penyimpanan pada suhu $4^{\circ} \mathrm{C}$ dan 2 hari setelah penyimpanan pada suhu $45^{\circ} \mathrm{C}$.

6) Viskositas (Lachman, 1994)

Sediaan pasta gigi dimasukkan ke dalam beacker glass $500 \mathrm{ml}$. Pengukuran dilakukan dengan menggunakan viskometer Brookfield tipe RV-DVE, spindel no 7 dicelupkan kedalam sediaan pasta gigi sampai garis tanda batas yang ada pada spindel, kemudian nyalakan alat tersebut lalu atur kecepatan mulai dari 2, 4, 6, 10, 20,30, 60, dan 100 rpm. Lalu dibalik kecepatannya dari 100,60,30, 20, 10, 6, 4, dan 2 rpm. Hasil pembacaannya dicatat.

Analisa Data

Analisa data dilakukan terhadap hasil uji viskositas yang diperoleh pada setiap formula, dianalisa menggunakan uji two way ANOVA pada taraf kepercayaan 95\% $(\alpha=0,05)$ untuk melihat adanya perbedaan atau tidak. Kemudian apabila terdapat perbedaan maka dilanjutkan dengan uji Tuckey-HSD (Honestly Significant Differences) 
Tabel III. Hasil Organoleptis dan Susut Pengeringan Ekstrak Kental Daun Sosor Bebek

\begin{tabular}{ccccc}
\hline Bentuk & Warna & Bau & Rasa & $\begin{array}{c}\text { Susut } \\
\text { Pengeringan }\end{array}$ \\
\hline Cairan kental & Coklat tua kehitaman & Khas & Asam & $23,3732 \%$. \\
\hline
\end{tabular}

Tabel IV. Uji Kandungan Ekstrak Etanol 96\% Daun Sosor Bebek

\begin{tabular}{cccc}
\hline Kandungan kimia & Pereaksi & Hasil pengamatan & Keterangan \\
\hline Saponin & Air dan dikocok & Timbul busa & + \\
Flavonoid & Mg dan $\mathrm{HCl}$ pekat & Berwarna merah & + \\
& & & \\
\hline
\end{tabular}

\section{HASIL DAN PEMBAHASAN}

Pembuatan ekstrak etanol $96 \%$ daun sosor bebek

Hasil ekstraksi didapatkan ekstrak kental seberat 385,25 g dengan rendemen sebesar 2,57\%.

Hasil uji karaterisasi ekstrak etanol $96 \%$ daun sosor bebek

1. Hasil uji organoleptik dan susut pengeringan

Hasil uji organoleptik tercantum pada tabel III

2. Identifikasi kandungan ekstrak etanol $96 \%$ daun sosor bebek.

Hasil uji kandungan ekstrak etanol tercantum pada tabel IV.
Hasil Evaluasi pasta gigi

1. Organoleptik

Pengamatan organoleptik pada sediaan pasta gigi dilakukan selam 6 minggu. Hasil pengamatan organoleptik selama penyimpanan pada suhu kamar tidak mengalami perubahan bau, warna, dan homogenitas pada semua formula pasta gigi ekstrak etanol $96 \%$ daun sosor bebek. Hasil tersebut menunjukkan bahwa bahan pengikat dan humektan yang digunakan dalam sediaan pasta gigi mampu mencegah terjadinya pemisahan fase sehingga sediaan tetap terlihat homogen dan stabil. Hasil pengamatan organoleptik dapat dilihat pada tabel V. 
Tabel V. Karakterisasi Pasta Gigi Ekstrak Etanol 96\% Daun Sosor Bebek

\begin{tabular}{ccccc}
\hline Formula & Tampilan fisik & Bau & Warna & Homogenitas \\
\hline F1 & Kental & Mint & Krem & Homogen \\
F2 & Kental & Mint & Krem & Homogen \\
F3 & Semi solid & Mint & $\begin{array}{c}\text { Agak } \\
\text { kekuningan } \\
\text { Homogen }\end{array}$ & Agak \\
F4 & Semi solid & Mint & Homogen \\
& & & kekuningan & \\
F5 & Semi solid & Mint & Kekuningan & Homogen \\
F6 & Kental & Mint & Krem & Homogen \\
F7 & Kental & Mint & Krem & Homogen \\
F8 & Semi solid & Mint & Krem & Homogen \\
F9 & Semi solid & Mint & Krem & Homogen \\
F10 & Semi solid & Mint & Krem & Homogen \\
\hline
\end{tabular}

1. Pengukuran $\mathrm{pH}$

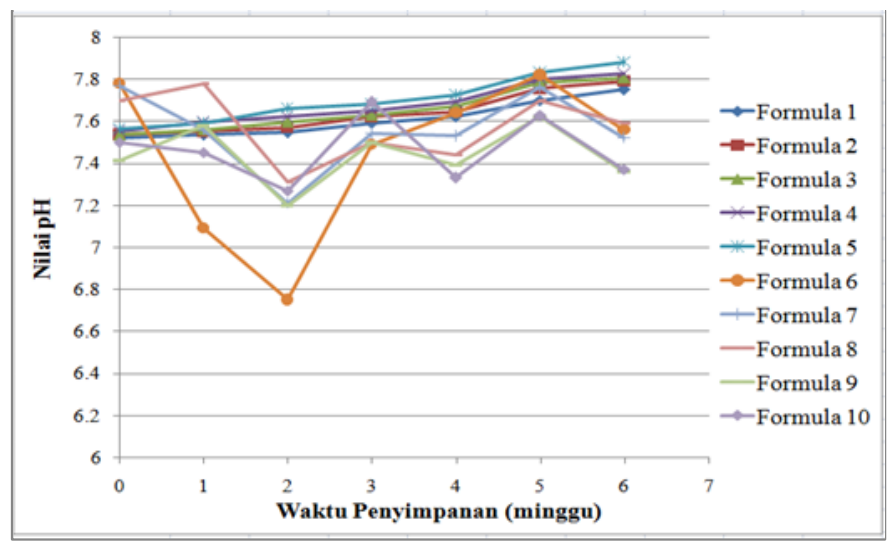

Gambar 1. Grafik pengukuran $\mathrm{pH}$

Hasil pemeriksaan dapat dilihat pada Gambar 1. Dimana nilai $\mathrm{pH}$ tersebut masih memenuhi persyaratan mutu pasta gigi pada SNI 12-3524-1995 yaitu 4,5 - 10,5. Diharapkan adanya $\mathrm{pH}$ yang memenuhi persyaratan SNI, sediaan pasta gigi ekstrak etanol 96\% daun sosor bebek tidak mengiritasi mukosa mulut. Bahan pengikat dan humektan yang digunakan dalam formula pasta gigi memiliki nilai $\mathrm{pH}$ stabilitas $6-9, \quad$ dengan meningkatnya konsentrasi bahan pengikat dan humektan maka akan merubah konsentrasi $\left[\mathrm{OH}^{-}\right]$dan $\left[\mathrm{H}^{+}\right]$ yang mengakibatkan bervariasinya nilai $\mathrm{pH}$ sediaan.

2. Pengukuran tinggi busa

$$
\text { Pengukuran tinggi busa }
$$

dilakukan pada formula 1 sampai 10 diawal pembuatan sediaan 


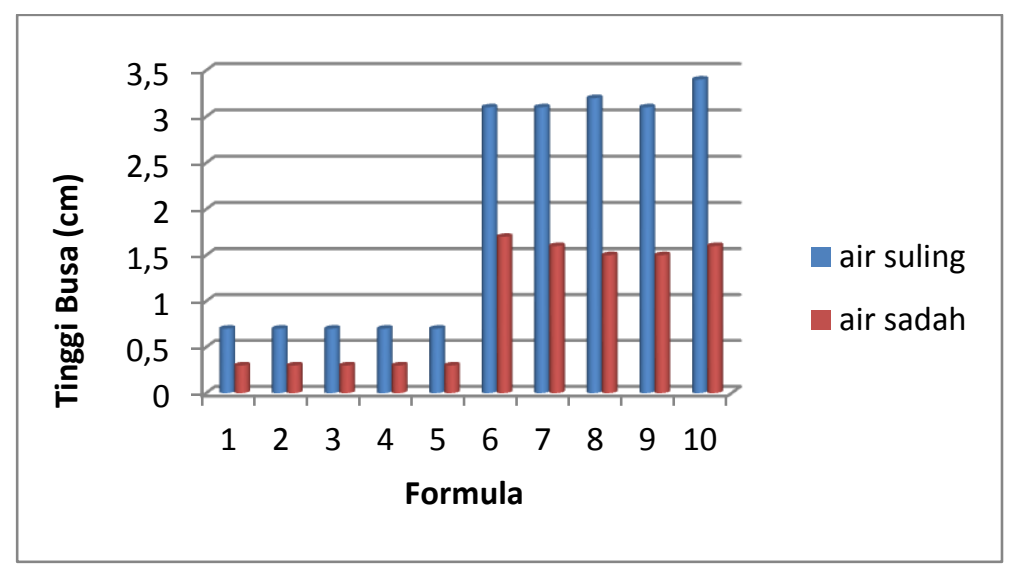

Gambar 2. Grafik pengukuran tinggi busa

dengan gelas ukur mengunakan 2 jenis air yaitu air sadah dan air suling. Pengukuran tinggi busa dalam air sadah menghasilkan busa yang lebih sedikit daripada pembentukan busa dalam air suling. Hal ini disebabkan adanya air sadah yang mengandung logam kalsium dan magnesium yang mengikat ionion surfaktan, sehingga menghambat kerja surfaktan dalam hal membentuk busa. Hasil dapat dilihat pada gambar 2 .

\section{Freeze thaw}

Pada sediaan pasta gigi ekstrak etanol 96\% daun sosor bebek dengan Xanthan gum-gliserin terlihat bahwa tidak terjadi pemisahan pada setiap siklusnya. Penggunaan xanthan gum sebagai pengikat membuat pasta gigi tidak mudah mengalami pemisahan fase. Hal ini menunjukkan pasta gigi ekstrak etanol $96 \%$ daun sosor bebek stabil dalam penyimpanan.

Pasta gigi ekstrak etanol 96\% daun sosor bebek dengan natrium karboksimetil selulosa-sorbitol terlihat pemisahan pada konsentrasi sorbitol 10 dan $20 \%$, yaitu ditandai dengan adanya lapisan cair berwarna krem di atas permukaan sediaan. Rendahnya konsentrasi sorbitol menyebabkan ikatan antara fase padat dengan fase pendispersinya putus akibat penyimpanan pada suhu ekstrim sehingga menimbulkan pemisahan antar fase. 


\section{Sentrifugasi}

Hasil pengamatan pada tabel VI dari formula yang tidak mengalami pemisahan fase karena banyaknya jumlah ikatan antara fase padat dan fase pendispersi sehingga dapat bertahan akibat goncangan yang dihasilkan dari gaya sentrifugal. Pengujian pada $3500 \mathrm{rpm}$ selama 5 jam sudah memberikan gambaran pada pasta gigi ekstrak etanol $96 \%$ daun sosor bebek cukup stabil.

\section{Viskositas}

Hasil pemeriksaan dapat dilihat pada grafik yang ditunjukkan pada Gambar 3 dan 4. Sorbitol adalah bahan higroskopis yang mempunyai sifat dapat mengikat air pada bahan sehingga kadar air menurun dan viskositas meningkat (Purnomo, 1995). Semakin meningkat konsentrasi sorbitol dalam sediaan mengakibatkan makin banyak air yang terikat sehingga meningkatkan viskositas sediaan.

Xanthan gum bekerja dengan cara mengikat komponen air melalui ikatan hidrogen. Semakin bertambahnya konsentrasi xanthan gum maka jumlah air yang terikat akan bertambah, sehingga viskositasnya juga meningkat. Viskositas merupakan salah satu faktor yang mempengaruhi stabilitas fisik sediaan semi padat, kenaikan viskositas umumnya mengurangi kemungkinan creaming atau pengendapan (Lachman, 1994). Adanya kenaikan viskositas pada peningkatan konsentrasi xanthan gum, membuat sediaan stabil karena pergerakan air cenderung sulit dan kemungkinan terjadinya pemisahan sulit terjadi. Dalam hal ini, adanya peningkatan konsentrasi xanthan gum dapat meningkatkan stabilitas fisik pasta gigi dilihat dari adanya peningkatan viskositas.

\section{KESIMPULAN}

Penggunaan pengikat lebih efektif dalam meningkatkan konsistensi dan viskositas sediaan pasta gigi dibandingkan dengan penggunaan pelembab (humektan) sehingga menghasilkan sediaan pasta gigi ekstrak etanol 96\% daun sosor bebek (Bryophyllum pinnatum [Lam.] Oken)dengan sifat fisik yang lebih baik. 
Tabel VI . Hasil pengamatan sentrifugasi

\begin{tabular}{cc}
\hline Formula & Kecepatan (3500 rpm) \\
\hline F1 & + \\
F2 & + \\
F3 & - \\
F4 & - \\
F5 & - \\
F6 & - \\
F7 & - \\
F8 & - \\
F9 & - \\
F10 & - \\
\hline
\end{tabular}

Keterangan: $(-)=$ tidak terjadi pemisahan, $\quad(+)=$ terjadi pemisahan

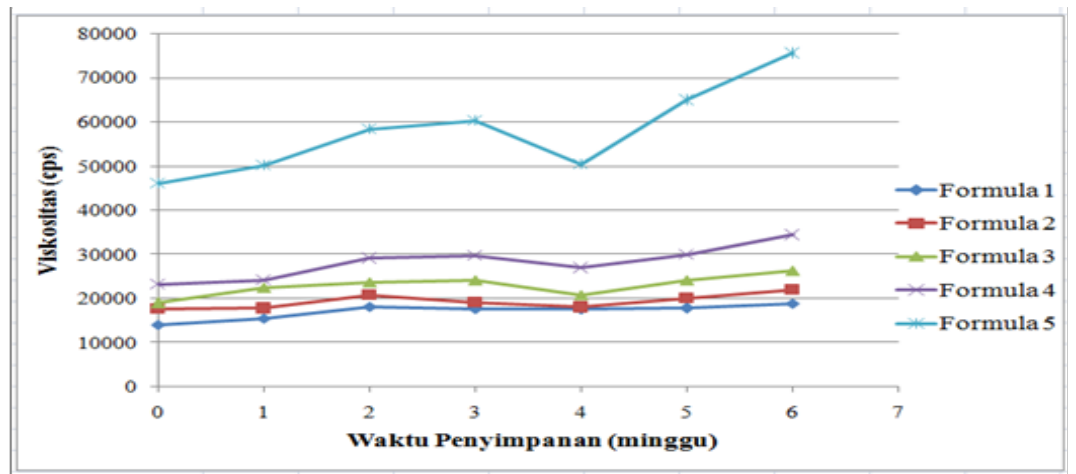

Gambar 3. Grafik hasil viskositas pasta gigi ekstrak etanol $96 \%$ daun sosor bebek dengan Natrium Karboksimetil Selulosa - sorbitol (spindel nomor 7 dan kecepatan 30 rpm)

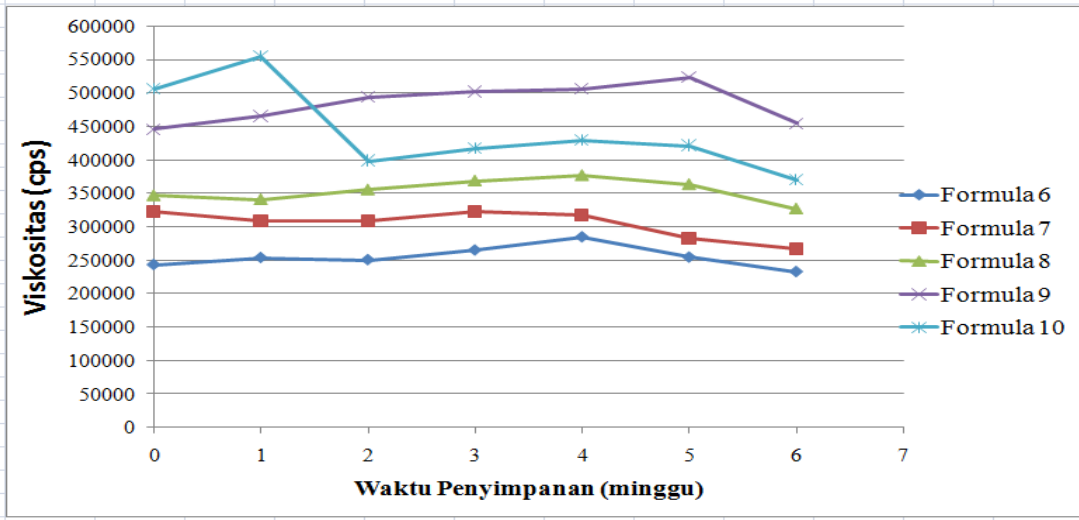

Gambar 4. Hasil viskositas pasta gigi ekstrak etanol $96 \%$ daun sosor bebek dengan Xanthan gum - gliserin (spindel nomor 7 dan kecepatan $2 \mathrm{rpm}$ ) 


\section{DAFTAR PUSTAKA}

Departemen Kesehatan RI, 1979, Materia Medika Indonesia Jilid III, Departemen Kesehatan RI, Jakarta : 170.

Departemen Kesehatan RI, 1995, Farmakope Indonesia Edisi $I V$, Departemen Kesehatan

RI, Jakarta : 7, 159, 413, 551, 595, 713, 750, 1039.

Departemen Kesehatan RI, 2000, Buku Panduan Teknologi Ekstrak, Direktorat Jenderal Pengawasan Obat dan Makanan, Jakarta : 6, 11-14.

Departemen Kesehatan RI, 2008, Farmakope Herbal Indonesia Edisi I, Departemen Kesehatan RI, Jakarta : 174-175.

Harbone J, 1987, Metode Fitokimia Penuntun Cara Modern Menganalisis Tumbuhan Terbitan Kedua, Terjemahan: Kosasih Padmawinata dan Iwang Soediro, ITB Press, Bandung : 97.

Jackson, E.B., 1995, Sugar Confectionery Manufacture, 2nd ed, Cambridge University Press, Cambridge.

Lachman, L., Lieberman, A., Kanig, L., 1994, Teori dan Praktek
Farmasi Industri Edisi II, Terjemahan: Siti Suyatmi. UI-Press, Jakarta : 10791088.

Lieberman, A., Rieger, M., Banker, S., 1996, Pharmaceutical Dosage Forms Disperse Systems Volume 2, Marcel Dekker, Inc. New York : 423440.

Mitsui, T., 1997, New Cosmetic Science, Elsevier, Amsterdam : 479-487.

Oktorita, A., 2010, Standarisasi dan Uji Konsentrasi Hambat Minimum terhadap Streptococcus mutans dari Ekstrak Air dan Etanol Daun Sosor Bebek (Kalanchoe pinnata [Lamk.] Pers.). Skripsi, Fakultas Farmasi Universitas Pancasila, Jakarta : 49 .

Purnomo, H., 1995, Aktivitas Air dan Peranannya dalam Pengawetan Pangan, UI Press, Jakarta.

Rieger, M., 1985, Surfactants in Cosmetics, Volume 16. Marcel Dekker, inc. New York : 333.

SNI 12-3524-1995, Pasta Gigi, Dewan Standarisasi Nasional, Jakarta : 1-16. 